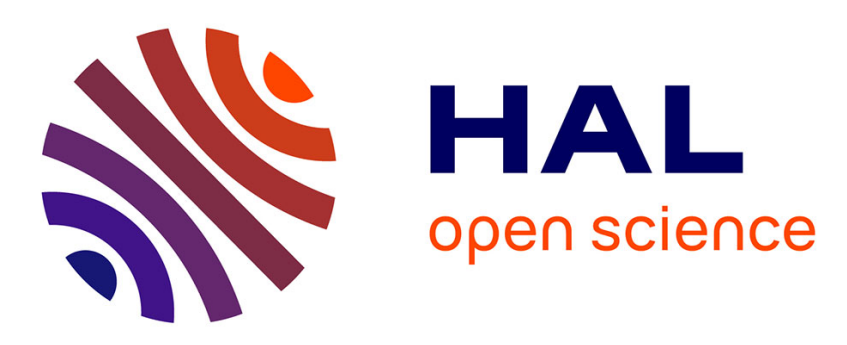

\title{
Influence of a cationic surfactant on adsorption of p-nitrophenol by a magsorbent based on magnetic alginate beads
}

Layaly Obeid, Nadia El Kolli, Delphine Talbot, Mathias Welschbillig, Agnès Bée

\section{To cite this version:}

Layaly Obeid, Nadia El Kolli, Delphine Talbot, Mathias Welschbillig, Agnès Bée. Influence of a cationic surfactant on adsorption of p-nitrophenol by a magsorbent based on magnetic alginate beads. Journal of Colloid and Interface Science, 2015, 457 (2015-11-01), pp.218-224. 10.1016/j.jcis.2015.07.017 . hal-01176196

\section{HAL Id: hal-01176196 \\ https: / hal.sorbonne-universite.fr/hal-01176196}

Submitted on 15 Jul 2015

HAL is a multi-disciplinary open access archive for the deposit and dissemination of scientific research documents, whether they are published or not. The documents may come from teaching and research institutions in France or abroad, or from public or private research centers.
L'archive ouverte pluridisciplinaire HAL, est destinée au dépôt et à la diffusion de documents scientifiques de niveau recherche, publiés ou non, émanant des établissements d'enseignement et de recherche français ou étrangers, des laboratoires publics ou privés. 


\section{Influence of a cationic surfactant on adsorption of p-nitrophenol by a magsorbent based on magnetic alginate beads}

Layaly Obeid $^{\mathrm{a}, \mathrm{b}, \mathrm{c}}$, Nadia El Kolli ${ }^{\mathrm{a}, \mathrm{b}}$, Delphine Talbot ${ }^{\mathrm{a}, \mathrm{b}}$, Mathias Welschbillig ${ }^{\mathrm{c}}$, Agnès Bée ${ }^{\mathrm{a}, \mathrm{b} *}$ 1ghannoum@hotmail.fr, nelkolli@yahoo.fr, $\underline{\text { delphine.talbot@upmc.fr, }}$ m.welschbillig@utilities-performance.com,agnes.bee@upmc.fr

a Sorbonne Universités, UPMC Univ Paris 06, UMR 8234, PHENIX, F-75005, Paris, France

${ }^{\mathrm{b}}$ CNRS, UMR 8234, PHENIX, F-75005, Paris, France

${ }^{c}$ Utilities Performance - Eau et Industrie 14, Rue des Écoles Saint-Nicolas-des-Eaux 56930 Pluméliau (France)

* Corresponding Author:

Mail: agnes.bee@upmc.fr

Tel: 33144273098

Address: Sorbonne Universités, UPMC Univ Paris 06, UMR 8234, PHENIX, case courrier 51, F-75005, Paris, France.

The paper focuses on the removal of p-nitrophenol by an adsorption process. A magnetic adsorbent was synthesized by encapsulation of magnetic functionalized nanoparticles using alginate as a green biopolymer matrix. A cationic surfactant, cetylpyridinium chloride $(\mathrm{CPyCl})$, was used to confer a hydrophobic character to the magnetic beads and thus to promote their adsorption efficiency. The effect of different parameters such as initial concentrations of both PNP and $\mathrm{CPyCl}$, contact time and solution $\mathrm{pH}$ value on the adsorption of PNP in the presence of $\mathrm{CPyCl}$ was investigated. It should be noted that combination of magnetic and adsorption properties in a same material is an interesting challenge which could overcome the recovery problems of pollutant-loaded adsorbent. 


\author{
Abbreviations: \\ p-nitrophenol (PNP) \\ cetylpyridinium chloride $(\mathrm{CPyCl})$
}

Keywords: Ferrofluid, surfactant, alginate, magsorbent, magnetic, beads, adsorption, cetylpyridinium chloride, water remediation, alginate bead, adsolubilisation, p-nitrophenol

\title{
Influence of a cationic surfactant on adsorption of p-nitrophenol by a magsorbent based on magnetic alginate beads
}

Layaly Obeid $^{\mathrm{a}, \mathrm{b}, \mathrm{c}}$, Nadia El Kolli ${ }^{\mathrm{a}, \mathrm{b}}$, Delphine Talbot ${ }^{\mathrm{a}, \mathrm{b}}$, Mathias Welschbillig ${ }^{\mathrm{c}}$, Agnès Bée $\mathrm{e}^{\mathrm{a}, \mathrm{b} *}$ 1ghannoum@hotmail.fr, nelkolli@yahoo.fr, delphine.talbot@upmc.fr, m.welschbillig@utilities-performance.com,agnes.bee@upmc.fr 
a Sorbonne Universités, UPMC Univ Paris 06, UMR 8234, PHENIX, F-75005, Paris, France

${ }^{\mathrm{b}}$ CNRS, UMR 8234, PHENIX, F-75005, Paris, France

${ }^{c}$ Utilities Performance - Eau et Industrie 14, Rue des Écoles Saint-Nicolas-des-Eaux 56930

Pluméliau (France)

* Corresponding Author:

Mail: agnes.bee@upmc.fr

Tel: 33144273098

Address: Sorbonne Universités, UPMC Univ Paris 06, UMR 8234, PHENIX, case courrier 51, F-75005, Paris, France. 


\begin{abstract}
The paper focuses on the efficient removal of a weakly ionisable pollutant from water by an adsorption process; p-nitrophenol (PNP) was selected as a representative model pollutant. A magnetic adsorbent (called magsorbent) was synthesized by encapsulation of magnetic functionalized nanoparticles using alginate as a green biopolymer matrix. A cationic surfactant, cetylpyridinium chloride $(\mathrm{CPyCl})$, was used to confer a hydrophobic character to the magnetic beads and thus to promote their adsorption capacity for non-ionisable or weakly ionisable pollutants. The effect of different parameters such as initial concentrations of both $\mathrm{PNP}$ and $\mathrm{CPyCl}$, contact time and solution $\mathrm{pH}$ value on the adsorption of PNP in the presence of $\mathrm{CPyCl}$ was investigated. The experimental adsorption data showed a maximum sorption capacity close to $140 \mathrm{mg} / \mathrm{g}$, which appears satisfactory when compared to literature values. In our experimental conditions, kinetic data indicate that $50 \%$ of the PNP was removed within 4 min whereas $90 \%$ adsorption was attained within 2 hours. It should be noted that combination of magnetic and adsorption properties in a same material is an interesting challenge which could overcome the recovery problems of pollutant-loaded adsorbent.
\end{abstract}

Keywords: Ferrofluid, surfactant, alginate, magnetic, adsorption, cetylpyridinium chloride, water remediation, adsolubilisation, p-nitrophenol 


\section{Introduction}

Sustainable water supply has become a real challenge. Indeed, in today's world, many chemical compounds resulting from human activity are found in water and among them, some act as endocrine disruptors. In order to improve the quality of water, and especially water for human consumption, various processes are developed. Among them, adsorption is widely used for being of low-cost, easy to handle and efficient for the removal of pollutants. Today, activated carbon (AC) is one of the most efficient adsorbents used in industrial processes of water purification due to its high porosity and very large surface area. Despite its efficiency, its use is limited by process engineering difficulties due to its high regeneration cost and loss of materials during its recovery.

To overcome these limitations, cost-effective and environmental friendly materials such as natural biopolymers have been extensively studied to remove pollutants from water by an adsorption process [1-9]. Moreover, due to the encapsulation ability of these biopolymers, advanced materials could be developed to perform adsorption process with subsequent separation. In this framework, the entrapment of magnetic nanoparticles in biopolymer matrix has received considerable attention in recent years. Indeed, the use of magnetic adsorbents (called here magsorbents) is a promising way due to their easy and fast removal from water through the application of an external field [10-12]. Several efficient magnetic adsorbents have been reported in the literature but most of them are especially effective in the removal of cationic or anionic pollutants [13-18]. The difficulty increases for removing of weakly ionisable or non-ionic organic pollutants. The use of a surfactant, which confers a hydrophobic character to the adsorbent, could be an efficient approach for the removal of such pollutants [19-27]. If the effects of surfactants on the sorption of organic compounds have been extensively studied for the extraction and preconcentration of various organic pollutants, few studies report the removal of hydrophobic compounds by magnetic adsorbents modified with a surfactant [28-30] and even less by magnetic biogels. The purpose of this 
study was thus to provide a material that has both magnetic properties and efficiency in the removal of weakly ionisable organic compounds by using a surfactant; cetylpyridinium chloride $(\mathrm{CPyCl})$ was selected as a representative cationic surfactant and alginate beads with encapsulated magnetic nanoparticles were used as magsorbent. The effect of the $\mathrm{pH}$ solution, time contact and initial concentrations of both surfactant $\mathrm{CPyCl}$ and pollutant p-nitrophenol (PNP) on adsorption by hydrophobically modified alginate beads was investigated and an adsorption mechanism was proposed. Regeneration experiments were also carried out. PNP was chosen because it is widely used in industries such as high-temperature coal conversion, petroleum refining, and resins and plastics manufacturing.

\section{Experimental}

\subsection{Materials}

Alginate is a natural linear polysaccharide extracted from seaweeds. It is constituted from $\beta$ d-mannuronate $(\mathrm{M})$ and $\alpha$-l-guluronate $(\mathrm{G})$ units arranged in blocks rich in $\mathrm{G}$ units (G-block) or M units (M-block) separated by blocks of alternating $\mathrm{G}$ and M units (MG-block) [31] . In addition, alginate is one of the main encapsulating compounds used in pharmaceutical compositions. The weight average molar weight $\left(\mathrm{M}_{\mathrm{w}}\right)$ and the number average molar weight $\left(\mathrm{M}_{\mathrm{n}}\right)$ of the used sodium alginate, obtained by gel permeation chromatography, are respectively equal to $2.07 \times 10^{5}$ and $1.08 \times 10^{5} \mathrm{~g} / \mathrm{mol}$, leading to a polydispersity index $\left(\mathrm{I}_{\mathrm{P}}\right)$ equal to 1.91. The amount of carboxylate functions of alginate ( $\mathrm{pKa}=3.4-4.2$ [1][32]) was obtained from the dosage of their sodium counter ions $\left([\mathrm{Na}]_{\text {alg }}\right)$ by atomic absorption spectrometry with a Perkin-Elmer Analyst 100 apparatus. It is equal to $4.2 \pm 0.1 \mathrm{mmol} / \mathrm{g}_{\mathrm{alg}}$. P-nitrophenol $\left(\mathrm{C}_{6} \mathrm{H}_{5} \mathrm{NO}_{3}\right.$ noted PNP) is a weak acid $(\mathrm{pKa} \approx 7.2[33,34])$ with a molecular weight equal to $139.11 \mathrm{~g} / \mathrm{mol}$. In aqueous solution, the molecular form of PNP appears colourless whereas its phenolic salt is bright yellow.

Cetylpyridinium chloride $\left(\mathrm{C}_{21} \mathrm{H}_{38} \mathrm{ClN} . \mathrm{H}_{2} \mathrm{O}\right.$ noted $\left.\mathrm{CPyCl}\right)$ is a quaternary ammonium surfactant with a pyridine group; its molecular weight is equal to $358 \mathrm{~g} / \mathrm{mol}$. The critical 
micelle concentration (CMC), as determined by surface tension measurements at $25^{\circ} \mathrm{C}$ by [35] is equal to $0.83 \mathrm{mmol} / \mathrm{L}$.

Calcium solutions were prepared by dissolving a known quantity of $\mathrm{CaCl}_{2}, 2 \mathrm{H}_{2} \mathrm{O}$ in distilled water.

The magnetic nanoparticles and magnetic alginate beads (called MagAlgbeads) used in this work were the same as that previously used in [36]. Briefly, magnetic material was a ferrofluid composed of maghemite $\left(\gamma \mathrm{Fe}_{2} \mathrm{O}_{3}\right)$ nanoparticles synthesized according to the Massart's method [37,38] and coated by citrate ions. Citrate is the basic form of citric acid, a triacid with pKa values equal to $2.79,4.30,5.65$ ) [39]. The stability of the ferrofluid is due to the ionisation of adsorbed citrate ions that are deprotonated at the $\mathrm{pH}$ value of the ferrofluid $(\mathrm{pH} \approx 7.5)$; the particles are then anionic ones with sodium counterions due to the carboxylate functions of adsorbed citrate. This magnetic material is a polydisperse system of rocklike nanoparticles, which can be described as spheres. Their mean diameter $\left(\mathrm{d}_{0}\right)$ and polydispersity index ( $($ obtained by a two-parameter fit of the magnetization curve are equal to $7.2 \mathrm{~nm}$ and 0.35 respectively [40]. The iron concentration of the ferrofluid, obtained by atomic absorption spectrometry, is equal to $1.33 \mathrm{~mol} / \mathrm{L}\left(106.4 \mathrm{~g}_{\text {maghemite }} / \mathrm{L}\right)$.

The magnetic alginate beads were prepared by dropping an alginate/ferrofluid mixture $\left(\mathrm{m}_{\text {alginate }} / \mathrm{m}_{\text {maghemite }}=0.5\right)$ into a $\mathrm{CaCl}_{2}$ solution and stored in deionized water. Beads appear brown due to the ferrofluid encapsulation (maghemite content $=64 \unrhd 2 \% \mathrm{w} / \mathrm{w}$ dry beads) and roughly spherical with a millimetric size (diameter $=3.3 \pm 0.2 \mathrm{~mm}$ ) (Figure 1$)$. The moisture content is equal to $94.6 \pm 0.1 \%$. Beads present magnetic properties; all beads are attracted when tested with a magnet. After the crosslinking process in the calcium bath, the counterions of the carboxylate functions coming from both alginate and citrate coating of the nanoparticles are calcium ions. Therefore, the number of negative sites of the beads (noted N) was deduced from $\mathrm{Ca}$ content obtained by atomic absorption spectrometry $(\mathrm{N}=1.5 \pm 0.1$ 
$\mathrm{mmol} / \mathrm{g}$ of dried beads). All products were purchased from Fluka and used without purification.

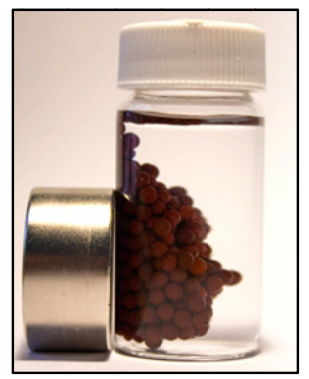

Figure 1: Photograph of the MagAlgbeads attracted with a small permanent NdFeB magnet (diameter: 2.5 cm; height: 1cm).

\subsection{Adsorption experiments}

Batch adsorption experiments were carried out at room temperature $\left(\approx 20^{\circ} \mathrm{C}\right)$. An appropriate mass of wet MagAlgbeads (noted $\mathrm{m}_{\mathrm{b}}$ ) was suspended into the cationic surfactant solution at a given initial concentration noted $\mathrm{C}_{0, \mathrm{CPyCl}}$. PNP solution was added into the mixture, its initial concentration is noted $\mathrm{C}_{0, \mathrm{PNP}}$. Initial concentrations were expressed in $\mathrm{mmol} / \mathrm{L}$ or in $\mathrm{mmol} / \mathrm{g}$ of dried beads. Distilled water was then added to complete to the chosen volume (V). The $\mathrm{pH}$ adjustments of the samples were realized with either $\mathrm{NaOH}$ or $\mathrm{HNO}_{3}$ solutions. The samples were shaken for a specified period at room temperature using an orbital shaker (IKA, KS 130). At suitable time intervals, a magnet was used to collect the magnetic beads. The concentrations of $\mathrm{PNP}$ and $\mathrm{CPyCl}$ remaining in solution $\left(\mathrm{C}_{\mathrm{CPyCl}}\right.$ and $\left.\mathrm{C}_{\mathrm{PNP}}\right)$ were obtained using an UV-Visible UVIKON XL (Secoman) spectrophotometer. The concentration of PNP was determined at $400 \mathrm{~nm}$ after adequate dilution in alkaline medium. A calibration curve was first performed to determine its molar extinction coefficient $\left(\varepsilon_{400, \mathrm{PNP}}=18103 \mathrm{Lcm}^{-1} \mathrm{~mol}^{-1}\right)$. The concentration of $\mathrm{CPyCl}$ was determined at $259 \mathrm{~nm}$ after adequate dilution. Its molar extinction coefficient $\left(\varepsilon_{259, \mathrm{CPyCl}}\right)$ obtained from the calibration curve at $259 \mathrm{~nm}$ is equal to $4271 \mathrm{Lcm}^{-1} \mathrm{~mol}^{-1}$. In the presence of PNP, as the two compounds adsorb at $259 \mathrm{~nm}, \mathrm{CPyCl}$ concentration in the two-component solution was obtained by using the additivity property of 
absorbance: $C_{C P y C l}=\frac{A_{259}-\varepsilon_{259, P N P} \times l \times C_{P N P}}{\varepsilon_{259, C P y C l} \times l}$ with $\mathrm{A}_{259}$, the absorbance of the mixture at 259 $\mathrm{nm} ; 1(\mathrm{~cm})$, the length of the cuvette; $\varepsilon_{259, \mathrm{PNP}}=3073 \mathrm{Lcm}^{-1} \mathrm{~mol}^{-1}$ (the molar extinction coefficient of PNP at $259 \mathrm{~nm}$ was obtained from a calibration curve of pure PNP at $259 \mathrm{~nm}$ ) and $\mathrm{C}_{\mathrm{PNP}}$, the concentration of PNP in the mixture obtained from the absorbance at $400 \mathrm{~nm}$ (PNP adsorbs alone at this wavelength). The amounts of adsorbed $\mathrm{CPyCl}$ or PNP (Q QPNP expressed in millimoles per gram of dry MagAlgbeads) were calculated from the difference between the initial and the final concentrations in the aqueous phase: $Q_{i}=$ $\frac{\left(C_{0, i}-C_{i}\right) \times V}{m_{b}}$, i being $\mathrm{CPyCl}$ or PNP. The amount of calcium ions remaining in the beads was deduced from the amount of calcium ions in the solution, obtained by atomic absorption spectrometry. Results of blank experiments without PNP were taken into the reference [36].

\subsection{Desorption experiments}

Desorption of PNP from magnetic beads was investigated. For the adsorption step, 7 identical samples were prepared by adding PNP $\left(\mathrm{C}_{0, \mathrm{PNP}}=0.124 \mathrm{mmol} / \mathrm{g}\right)$ to a solution containing $1.075 \mathrm{~g}$ magnetic alginate beads and $\mathrm{CPyCl}\left(\mathrm{C}_{0, \mathrm{CPyCl}}=1.28 \mathrm{mmol} / \mathrm{g}\right), \mathrm{pH}$ solution was close to 6.9. After 3 days shaking, the beads were magnetically separated from the solution and the adsorbed amounts of PNP and $\mathrm{CPyCl}$ were determined as previously. The beads were then added to $10 \mathrm{~mL}$ of a mixture ethanol/water at various compositions. At suitable time intervals, a magnet was used to collect the magnetic beads and the desorbed amounts of PNP and $\mathrm{CPyCl}$ were determined using UV-Visible Spectrophotometry.

\section{Results and discussion}

\subsection{Influence of CPyCl concentration on PNP adsorption}

The experimental data of the PNP removal by magnetic alginate beads in presence of increasing initial amounts of $\mathrm{CPyCl}\left(\mathrm{C}_{0, \mathrm{CPyCl}}\right)$ obtained at $\mathrm{pH} 6.6$ and at $72 \mathrm{~h}$ from the initial stage are shown in Figure 2, the initial concentration of PNP was fixed to $0.76 \mathrm{mmo} / \mathrm{L}$. Without surfactant, the removal efficiency of PNP by the beads is about $12 \%$. The removal of 
PNP then increases with the increase of $\mathrm{CPyCl}$ amount and the removal is found to be maximal for a $\mathrm{CPyCl}$ dose of $1.8 \mathrm{mmol} / \mathrm{g}$. At this stage, $90 \%$ PNP removal is achieved. A further increase of $\mathrm{CPyCl}$ concentration leads to a decrease of the amount of adsorbed PNP. The amount of $\mathrm{CPyCl}$ remaining in the solution $\left(\mathrm{C}_{\mathrm{CPyCl}}\right)$ is also reported in Figure 2. It could be noticed that the decrease of PNP adsorption occurs when the $\mathrm{CPyCl}$ concentration in solution is higher than the CMC of the surfactant $(0.83 \mathrm{mmol} / \mathrm{L})$. In this case, PNP desorption occurs when micellar solubilisation is preferred over adsorption by the beads.

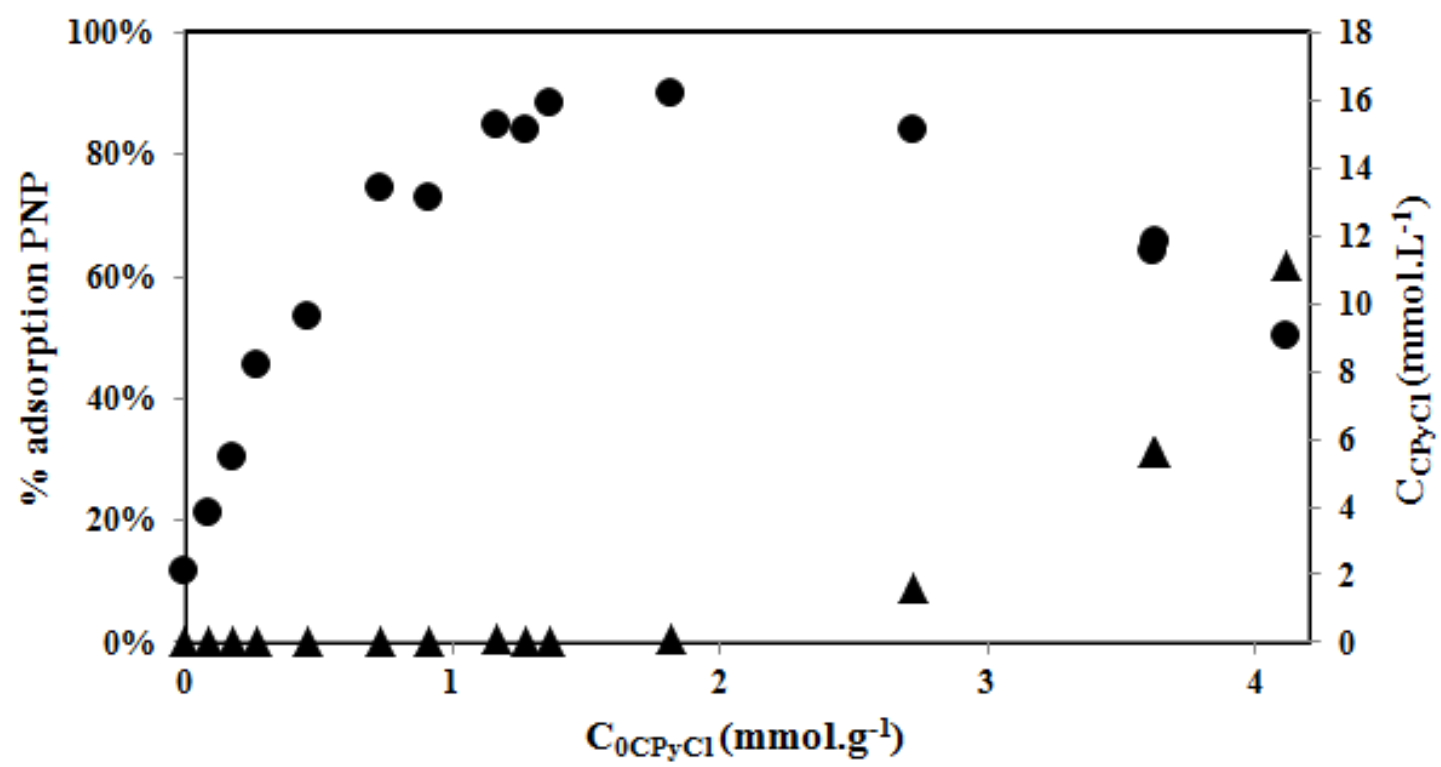

Figure 2: Influence of initial CPyCl concentration on PNP adsorption. \% adsorption PNP ( $\bullet$, left scale), amount of CPyCl remaining in the solution ( $\triangle$, right scale); $t=72 \mathrm{~h} ; \mathrm{V}=20 \mathrm{~mL}, \mathrm{~m}_{b}$ z.15 $\mathrm{g} ; \mathrm{pH}=6.6 \pm 0.3$; $C_{0, P N P}=0.76 \pm 0.09 \mathrm{mmol} / \mathrm{L}(0.123 \pm 0.005 \mathrm{mmol} / \mathrm{g})$.

The adsorption isotherm of $\mathrm{CPyCl}$ by alginate beads in presence of $0.76 \mathrm{mg} / \mathrm{L} \mathrm{PNP}$ is shown on Figure 3; the amount of adsorbed $\mathrm{CPyCl}\left(\mathrm{Q}_{\mathrm{CPyCl}}\right)$ is reported as a function of the amount of remaining $\mathrm{CPyCl}$ in the solution $\left(\mathrm{C}_{\mathrm{CPyCl}}\right)$. The plateau of isotherm corresponds to 2.7 $\mathrm{mmol} / \mathrm{g}$. Figure 3 reports also the variation of calcium ions remaining within the beads (noted $\left.[\mathrm{Ca}]_{\mathrm{b}}\right)$. As it was shown previously [36], surfactant adsorption occurs through the conjugated effects of electrostatic and hydrophobic interactions. The electrostatic forces occur between the positive charges of the surfactant molecules and the negative charges of the beads and 
surfactant replace the calcium counterions, which move outside the beads. On the other hand, surfactant aggregates appear in the beads due to hydrophobic interactions between their long alkyl chains. The removal of PNP by the beads is then due to its adsolubilisation within the adsorbed surfactant aggregates.

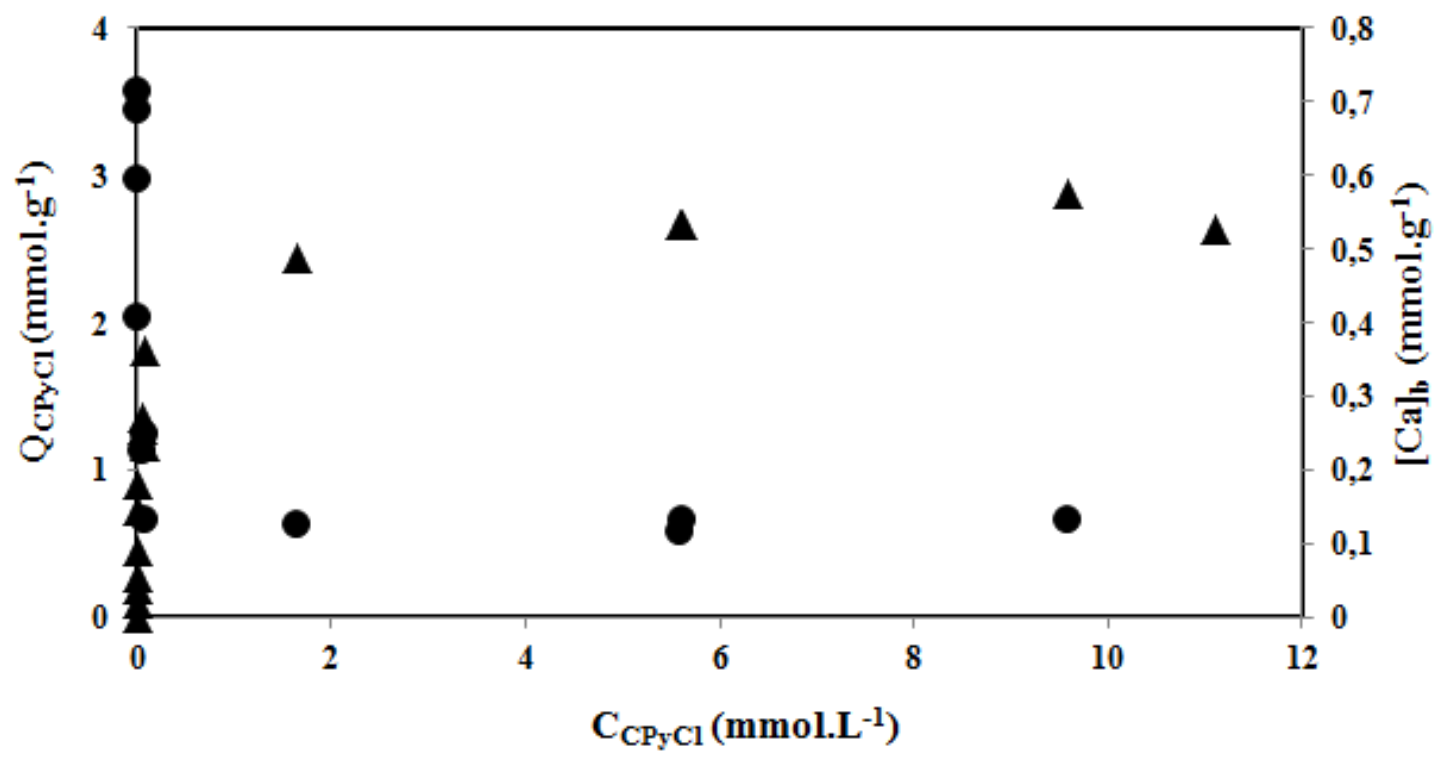

Figure 3: Adsorption isotherm of CPyCl in presence of PNP (4, left scale) and amount of calcium ions remaining within the beads ( $O$, right scale); $t=72 \mathrm{~h} ; \mathrm{V}=20 \mathrm{~mL}, \mathrm{~m}_{b}$ z.15 $\mathrm{g} ; \mathrm{pH}=6.6 \pm 0.3 ; C_{0, P N P}=0.76 \pm 0.09$ $\mathrm{mmol} / \mathrm{L}(0.123 \pm 0.005 \mathrm{mmol} / \mathrm{g})$.

In the following, the amount of added $\mathrm{CPyCl}$ will be equal to about $1.2 \mathrm{mmol} / \mathrm{g}$ to have a high removal of PNP and to limit the quantity of free surfactant within the solution.

\subsection{Adsorption isotherm of PNP}

Adsorption was built at $\mathrm{pH}$ around 6 in presence of a fixed amount of $\mathrm{CPyCl}\left(\mathrm{C}_{0, \mathrm{CPyCl}}=1.16\right.$ mmol.g ${ }^{-1}$ ) (Figure 4, left). The maximum amount of adsorbed PNP ( $\left.Q_{\max , P N P}\right)$, close to 1 $\mathrm{mmol} / \mathrm{g}(140 \mathrm{mg} / \mathrm{g})$, is comparable to that of other adsorbents reported in the literature where only activated carbon present a higher adsorption ([8,41-47]). 

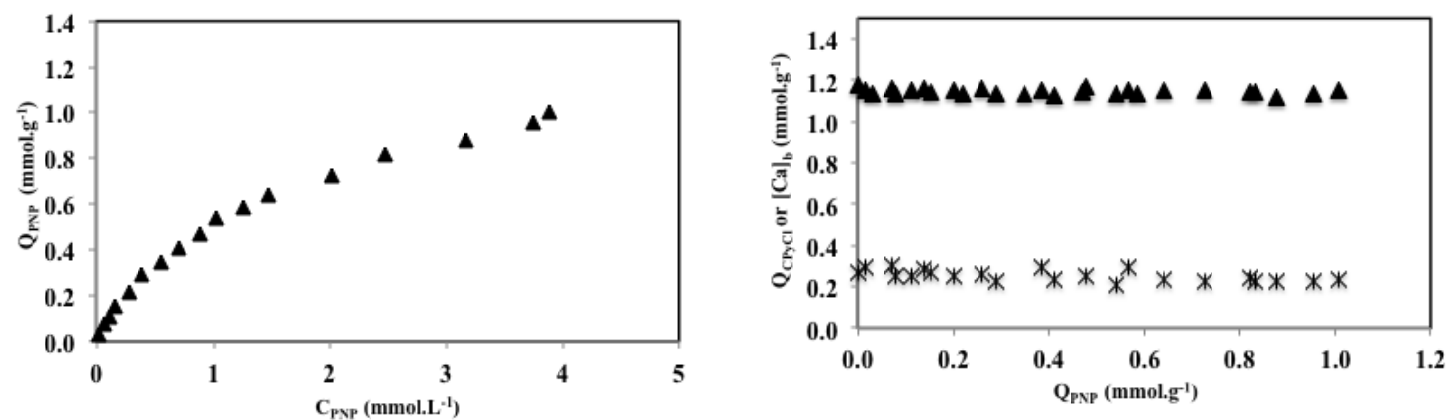

Figure 4: Left: adsorption isotherm of PNP in presence of CPyCl; right: Effect of adsorbed PNP on CPyCl

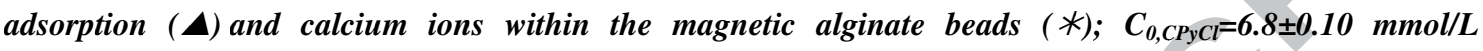
$(1.16 \pm 0.01 \mathrm{mmol} / \mathrm{g}) ; m_{b} \approx 1.075 \mathrm{~g} ; \mathrm{V}=10 \mathrm{~mL} ; t=72 \mathrm{~h}, \mathrm{pH} \approx 6$.

Figure 4 (right) represents the effect of the amount of adsorbed PNP on the adsorption of $\mathrm{CPyCl}$, the amount of calcium ions remaining within the magnetic alginate beads is also reported. By increasing the amount of adsorbed $\mathrm{PNP}$, adsorbed $\mathrm{CPyCl}$ remains constant $(1.15$ $\mathrm{mmol} / \mathrm{g}$ ) and represents $99 \%$ adsorption; it is equal to the amount of adsorbed $\mathrm{CPyCl}$ without PNP for the same concentration of added $\mathrm{CPyCl}$. As the same behaviour is observed for calcium ions, one can conclude that the ionic exchange between the calcium ions and $\mathrm{CPyCl}$ is not disturbed in presence of PNP.

The initial amount of calcium ions and the amount of calcium ions remaining in the beads after $\mathrm{CpyCl}$ adsorption being equal to $0.75 \mathrm{mmol} / \mathrm{g}$ and $0.25 \mathrm{mmol} / \mathrm{g}$ respectively, the number of monovalent negative sites of the beads neutralized by the surfactant molecules is then equal to $1.00 \mathrm{mmol} / \mathrm{g}(0.75-0.25) \times 2)$ (i.e. $66.7 \%$ of the total sites). The amount of $\mathrm{CPyCl}$ adsorbed by hydrophobic interactions with the chains of the surfactants already attached to the adsorption sites could be deduced, it is equal to $0.15 \mathrm{mmol} / \mathrm{g}(1.15-1.00)$, i. e. $13.4 \%$ of the total amount of adsorbed $\mathrm{CPyCl}$. This value is too low to consider a double layer of surfactants as proposed in [52] or even numerous surfactant aggregates. An adsorption of PNP via hydrophobic interactions with the carbon chains of the surfactant could be considered. 


\subsection{Effect of pH on PNP adsorption}

The $\mathrm{pH}$ value of the solution is an important parameter to control the adsorption process, since it may affect the ionisation of the carboxylate groups of the beads and, consequently, the amount of adsorbed surfactant, which is the driving force of PNP adsorption. Experiments were realized at $\mathrm{pH}$ varying from 2 to 12 with fixed concentrations of PNP and CPyCl. Firstly, Figure 5 (left) shows that adsorption of $\mathrm{CPyCl}$ is not altered by PNP; the curves representing the amounts of adsorbed $\mathrm{CPyCl}$ at varying $\mathrm{pH}$, with or without $\mathrm{PNP}$, are perfectly superimposed. Moreover, adsorbed $\mathrm{CPyCl}$ is constant between $\mathrm{pH} 3.2$ and $\mathrm{pH} 12$ $\left(\mathrm{Q}_{\mathrm{CPyCl}}=1.15 \mathrm{mmol} / \mathrm{g}\right)$. In this $\mathrm{pH}$ range, MagAlgbeads are negatively charged and the $\mathrm{CPyCl}$ adsorption is mainly attributed to electrostatic attraction. Due to the protonation of the carboxylate functions of the beads, a decrease of the $\mathrm{CPyCl}$ adsorption is observed for $\mathrm{pH}$ less than 3.2 [36].
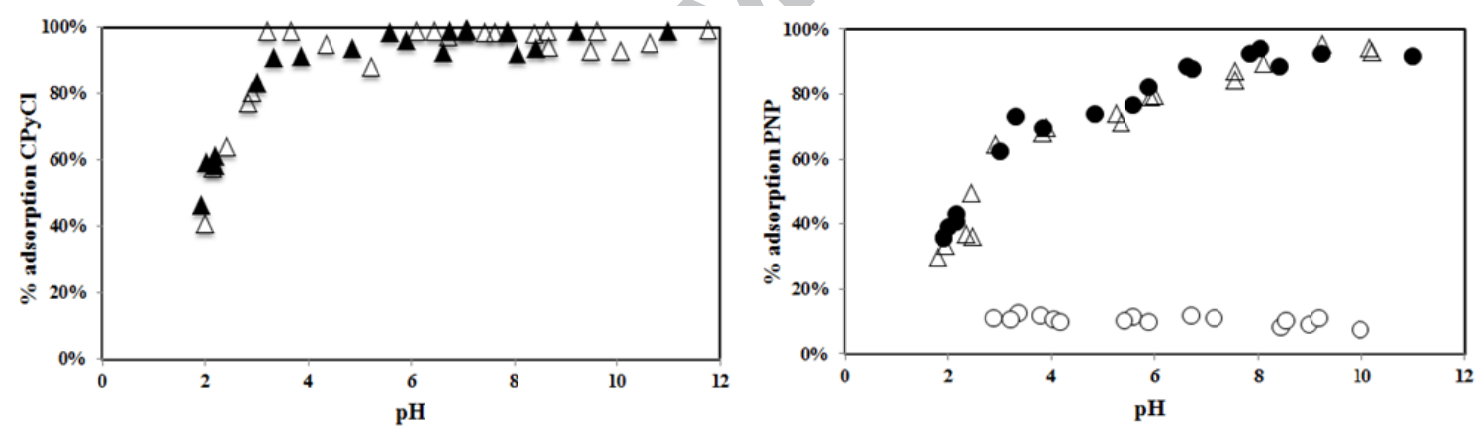

Figure 5: Left: effect of pH on CPyCl adsorption without PNP ( $\triangle)$ (data from [36]) and with PNP ( $\triangle)$; right : Effect of pH on PNP adsorption without surfactant (O) and in presence of CPyCl (O) or CTAB ( $\triangle)$. $C_{0, P N P}=0.730 \pm 0.003 \mathrm{mmol} / \mathrm{L} \quad(0.122 \pm 0.002 \mathrm{mmol} / \mathrm{g}), C_{0, C P y C l}=C_{0, C T A B}=7.1 \pm 0.2 \mathrm{mmol} / \mathrm{L} \quad\left(1.20 \pm 0.03 \mathrm{mmol} . \mathrm{g}^{-1}\right)$, $t=72 h, m_{b} \approx 2.15 g, V=20 m L$.

Figure 5 (right) represents the adsorption of $\mathrm{PNP}$ as a function of $\mathrm{pH}$ with and without $\mathrm{CPyCl}$. The effect of $\mathrm{CPyCl}$ on PNP adsorption is highly marked; the adsorption of PNP varies from $12 \%$ without $\mathrm{CPyCl}$ to $90 \%$ with $\mathrm{CPyCl}$ at $\mathrm{pH}$ above 7 . In presence of surfactant, the adsorption curve presents four parts: (i) in acid medium, the adsorption of PNP decreases from $72 \%$ at $\mathrm{pH} 3.3$ to $34 \%$ at $\mathrm{pH}$ 2. This is correlated to the decrease of $\mathrm{CpyCl}$ adsorption due to the protonation of the carboxylate functions of the beads; (ii) as the amount of 
adsorbed $\mathrm{CPyCl}$ remains constant between $\mathrm{pH} 3.3$ and $\mathrm{pH}$ 5.6, the amount of adsorbed PNP is also almost constant in this $\mathrm{pH}$ range $(0.088 \pm 0.003 \mathrm{mmol} / \mathrm{g}$ i.e. $72 \%$ of the initial concentration), adsorption is due to hydrophobic bonds between neutral form of PNP and the carbon chains of the surfactant; (iii) beyond $\mathrm{pH}$ 5.6, an increase of PNP adsorption occurs before to reach a constant value equal to $0.109 \pm 0.003 \mathrm{mmol} / \mathrm{g}$ ( $90 \%$ adsorption) between $\mathrm{pH}$ 7 and 12. The pKa value of PNP being equal to 7.2, its phenolate form is predominant in this $\mathrm{pH}$ range. The adsorption excess of PNP in alkaline medium may be due to electrostatic attraction between the negatively charged PNP and the surfactant molecules adsorbed by hydrophobic bonds and whose positive charges are not compensated by the carboxylate functions of the beads. The amount of hydrophobically adsorbed surfactant $(0.19 \mathrm{mmol} / \mathrm{g})$, obtained from the calcium ions remaining in the beads, corresponds to the number of available positive charges for adsorption of the phenolate form of PNP. It is quite sufficient to explain the additional adsorption of $\operatorname{PNP}(0.109-0.088=0.021 \mathrm{mmol} / \mathrm{g}$; i.e. $19.3 \%$ of total adsorbed PNP) at $\mathrm{pH}$ above 7 . The determination of the calcium ions concentration in the beads proves to be a convenient and easy way to understand the adsorption mechanisms of PNP in this $\mathrm{pH}$ range where the PNP adsorption is monitored by both hydrophobic and electrostatic interactions. To confirm our results, the same measurements were carried out with another cationic surfactant, cetyltrimetylammonium bromide (CTAB). As expected, the two curves reported on the Figure 5 (right) are well superimposed. This result is in accordance with a study of the adsorption of PNP by an anionic sediment in presence of $\mathrm{CPyCl}$ that showed that PNP was better adsorbed in its phenolate form [53]. In the same way, by using a zeolite modified with a cationic surfactant, the adsorption of non ionisable organic pollutants is not $\mathrm{pH}$-dependent while ionisable phenolic compounds are better adsorbed in basic medium due to positive charge of the adsorbent provided by the aggregates of surfactants [20]. 


\subsection{Effect of contact time on PNP adsorption}

The kinetics of the sorption process is an important parameter in order to evaluate the qualities of our magsorbent and its efficiency for pollutant removal. The uptake of PNP as a function of time by MagAlgbeads in the presence of the surfactant was conducted at an initial pH close to 6 using two methods. First, samples were prepared by adding PNP to a freshly prepared mixture of $\mathrm{CPyCl}$ and magnetic beads (method 1). In a second series of experiments, PNP was added $72 \mathrm{~h}$ after the preparation of the $\mathrm{CPyCl} / \mathrm{MagAlgbeads}$ mixture (method 2). In both cases, initial time corresponds to the addition of PNP. To know the effect of PNP on the kinetics of $\mathrm{CPyCl}$, the extent of $\mathrm{CPyCl}$ adsorption (method 1) has been plotted as a function of time $t$ and compared to the results obtained without PNP [36] (Figure 6, left).
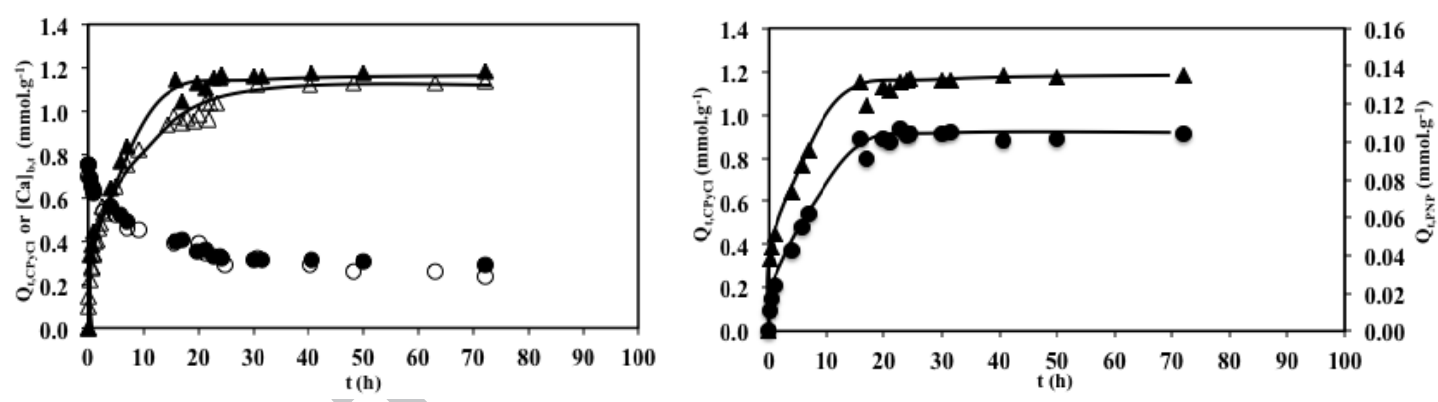

Figure 6: Method 1; Left: evolution of CPyCl adsorption and of the amount of $\mathrm{Ca}^{2+}$ ions remaining in the beads as a function of contact time; without PNP: $Q_{t, C P y C l}(\triangle),[C a]_{b, t}(O)$; with PNP: $Q_{t, C P y C l}(\Delta),[C a]_{b, t}$ (O). Right: Kinetics of adsorption of CPyCl (left scale: $\triangle$ ) and PNP (right scale: O). $m_{b} \neq .08 g, V=10 m L$, pH=6.7 \pm 0.4 . (See table 1 for initial concentrations of PNP and $\mathrm{CPyCl}$ ).

In both cases, the amount of adsorbed $\mathrm{CPyCl}\left(\mathrm{Q}_{\mathrm{t}, \mathrm{CPyCl}}\right)$ increases with an increase of time until it reaches a constant value attained within about $24 \mathrm{~h}$. The two curves are quite similar, with a slight acceleration of the surfactant adsorption in the presence of PNP, but the difference is too weak to draw conclusions. From Table 1 that reports the parameters of the kinetics, we note that $50 \%$ of $\mathrm{CPyCl}$ are adsorbed in $2-3 \mathrm{~h}$. In addition, the amounts of calcium ions remaining in the beads at equilibrium $\left([\mathrm{Ca}]_{b, t}\right)$ are very similar with and without 
PNP. This confirms that the ionic exchange between the surfactant and the calcium ions of the beads is not modified in presence of PNP.

\begin{tabular}{|c|c|c|c|c|c|c|c|}
\hline \multirow{2}{*}{ Method } & \multirow{2}{*}{ Compound } & \multicolumn{2}{|c|}{$\mathbf{C}_{0}$} & \multirow{2}{*}{$\begin{array}{c}\mathbf{Q}_{\mathrm{eq}} \\
(\mathrm{mmol} / \mathrm{g})\end{array}$} & \multirow{2}{*}{$\mathbf{t}_{50}$} & \multirow{2}{*}{$t_{90}$} & \multirow{2}{*}{$\begin{array}{c}{[\mathrm{Ca}]_{\mathrm{b}, \mathrm{eq}}} \\
(\mathrm{mmol} / \mathrm{g})\end{array}$} \\
\hline & & $(\mathrm{mmol} / \mathrm{g})$ & $(\mathrm{mmol} / \mathrm{L})$ & & & & \\
\hline Without PNP [36] & $\mathrm{CPyCl}$ & $1.15 \pm 0.01$ & $6.74 \pm 0.01$ & $1.13 \pm 0.01$ & $2.8 \mathrm{~h}$ & $25 \mathrm{~h}$ & $0.28 \pm 0.03$ \\
\hline \multirow{2}{*}{1} & $\mathrm{CPyCl}$ & $1.18 \pm 0.01$ & $6.91 \pm 0.01$ & $1.17 \pm 0,01$ & $2 \mathrm{~h}$ & $22 \mathrm{~h}$ & \multirow{2}{*}{$0.31 \pm 0.01$} \\
\hline & PNP & $0.122 \pm 0.001$ & $0.715 \pm 0.01$ & $0.103 \pm 0.003$ & $5 \mathrm{~h}$ & $24 \mathrm{~h}$ & \\
\hline & $\mathrm{CPyCl}$ & $1.28 \pm 0.01$ & $7.41 \pm 0.01$ & $1.27 \pm 0.01$ & - & f & \multirow{2}{*}{$0.25 \pm 0.01$} \\
\hline & PNP & $0.123 \pm 0.001$ & $0.712 \pm 0.001$ & $0.103 \pm 0.001$ & $4 \mathrm{~min}$ & $2 \mathrm{~h}$ & \\
\hline
\end{tabular}

Table 1: Kinetics parameters

Figure 6 (right) and Table 1 show the results of kinetics study for both PNP and CPyCl. As for $\mathrm{CPyCl}$, the rate of adsorption of PNP is rapid initially and then gradually increased before to reach a constant value after $24 \mathrm{~h}$. If the two curves have the same shape, the kinetics of the PNP adsorption is slower than that of $\mathrm{CpyCl} ; 50 \%$ of PNP removal took place within $5 \mathrm{~h}$ against $2 \mathrm{~h}$ for $\mathrm{CPyCl}$. With the method 1 , the time required to adsorb PNP is too long to use our magsorbent in a water treatment plant. To make our system more efficient, PNP is added to the system MagAlgbeads/CPyCl equilibrated within 3 days (method 2). In this way, we can observe the real adsorption kinetics of PNP. Initially, it was verified that equilibrium was well achieved in the case of $\mathrm{CPyCl}$. Its concentration was measured in the samples and the obtained values were plotted against time in Figure 7 (left), remaining amounts of calcium ions in the beads were also reported. As expected, the concentrations of adsorbed $\mathrm{CPyCl}$ and remaining calcium ions in the beads are constant with time and equal to the values obtained without PNP, the ionic exchange took place and the equilibrium was reached for the surfactant sorption. 

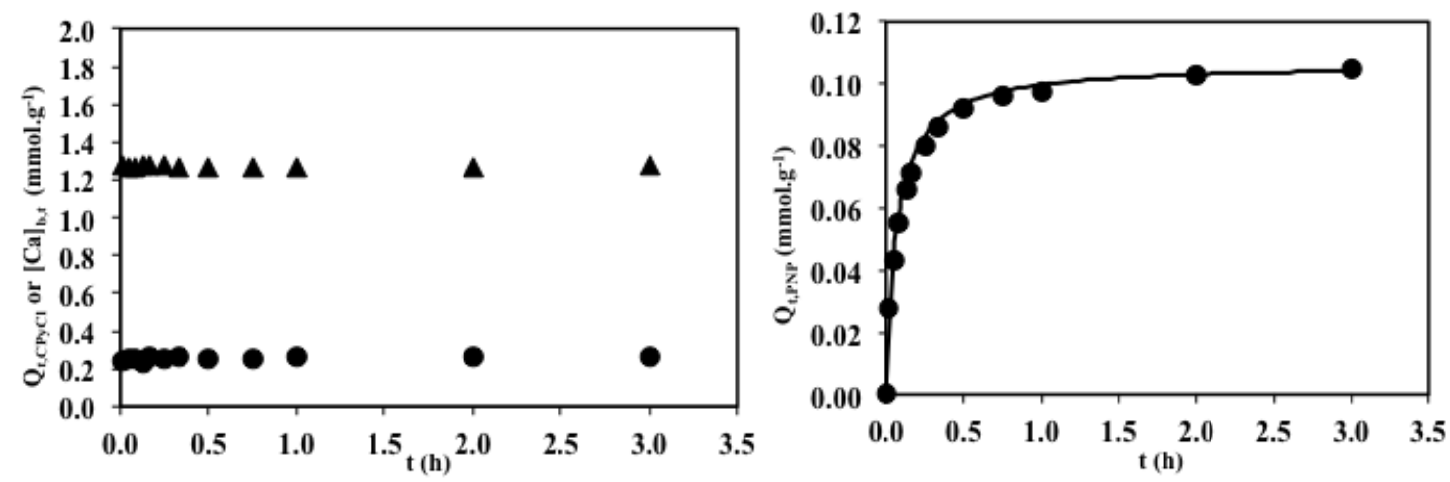

Figure 7: Method 2; Left: $Q_{t, C P y C l}(\Delta)$ and $[C a]_{b, t}(O)$ as a function of time $t$; Right: kinetics of the PNP adsorption; $C_{0, P N P}=0.712 \pm 0.001 \mathrm{mmol} / \mathrm{L}(0.123 \pm 0.001 \mathrm{mmol} / \mathrm{g}) ; C_{0, C P y C l}=7.41 \pm 0.01 \mathrm{mmol} / \mathrm{L} \quad(1.28 \pm 0.01$ $m m o l / g) ; p H=6.5 \pm 0.2, m_{b} \neq .075 g, V=10 m L$.

Figure 7 (right) and Table 1 report the results of the kinetics of the removal of PNP in the case of the method 2. If the amount of adsorbed PNP at equilibrium remains the same with both methods, the adsorption process of PNP is much faster with method 2. Indeed, 50\% removal of PNP takes place within 4 min and equilibrium is reached after 2 hours. In the case of method 2, $\mathrm{CPyCl}$ molecules are already adsorbed by the beads, their adsorption equilibrium is reached. The curve then represents only the kinetics of the PNP adsorption by the beads loaded with surfactant.

\subsection{Regeneration}

Regeneration of the beads was carried out with ethanol/water mixtures of varying composition. For this study, a set of identical samples of beads containing both $\mathrm{CPyCl}$ and PNP were prepared at $\mathrm{pH}$ 6.9. After $72 \mathrm{~h}$ shaking and magnetic separation, the amounts of adsorbed $\mathrm{CPyCl}$ and PNP determined from the solution analysis are similar to the values obtained previously, 99\% adsorption for $\mathrm{CPyCl}$ and $85 \%$ for PNP. Beads are then introduced into the regeneration mixture. In a first series of experiments, the supernatant was collected after 6h shaking and analysed, the amounts of desorbed $\mathrm{CPyCl}$ and PNP are reported in the Table 2. Desorption of PNP increases with the increase of ethanol amount in the mixture; with pure ethanol, $94 \%$ of PNP are desorbed while $86 \%$ of $\mathrm{CPyCl}$ remain adsorbed. In a second series of experiments, beads with the same amounts of adsorbed $\mathrm{CPyCl}$ and PNP were 
introduced in $10 \mathrm{~mL}$ of pure ethanol for variable periods of time. The results reported in the Table 2 show that 1 min shaking in pure ethanol is sufficient to remove about $50 \%$ of PNP. Ethanol is then a good way for beads regeneration.

\begin{tabular}{|c|c|c|c|}
\hline Ethanol/water (v/v) & $\mathbf{t}(\mathbf{m i n})$ & $\mathbf{P N P}_{\text {desorbed }}$ & $\mathbf{C P y C l}_{\text {desorbed }}$ \\
\hline $20 / 80$ & 360 & $41 \%$ & $1 \%$ \\
\hline $50 / 50$ & 360 & $91 \%$ & $7 \%$ \\
\hline Pure ethanol & 360 & $94 \%$ & $14 \%$ \\
\hline Pure ethanol & 5.0 & $70 \%$ & $7 \%$ \\
\hline Pure ethanol & 1.0 & $47 \%$ & $5 \%$ \\
\hline Pure ethanol & 0.5 & $27 \%$ & $3 \%$ \\
\hline
\end{tabular}

Table 2: PNP desorption in ethanol/water mixtures; $C_{0, P N P}=0.719 \pm 0.001 \mathrm{mmol} / \mathrm{L}(0.124 \pm 0.001 \mathrm{mmol} / \mathrm{g})$, $C_{0, C P y C l}=7.2 \pm 0.3 \mathrm{mmol} / \mathrm{L}(1.25 \pm 0.05 \mathrm{mmol} / \mathrm{g}), m_{b} \neq .08 \mathrm{~g}, \mathrm{pH}_{\text {adsorption }}=6.9, t_{\text {adsorption }}=3 \mathrm{days}, \mathrm{V}=10 \mathrm{~mL}$.

\section{Conclusion}

This study showed that the presence of a surfactant significantly enhances the adsorption of a weakly ionisable pollutant, p-nitrophenol, by magnetic alginate beads. The maximum adsorption capacity of the beads, equal to $140 \mathrm{mg} / \mathrm{g}$, appears satisfactory when compared to literature values. Moreover, the removal of $50 \%$ p-nitrophenol takes place within 4 min. It has been also demonstrated that the $\mathrm{pH}$ value of the solution plays a crucial role in $\mathrm{p}$ nitrophenol adsorption. In addition, regeneration tests in ethanol were successfully carried out. A major challenge in the field of adsorption is to identify the mechanisms by which adsorption process occurs. The fact that surfactant, p-nitrophenol and calcium were quantified allows supporting the mechanistic conclusions, which are developed. We showed that the ionic exchange between the cationic surfactant and the calcium ions of the beads was not modified by p-nitrophenol. Hydrophobicity thus acquired by the beads thanks to the surfactant is responsible of their efficiency for p-nitrophenol adsorption. If adsorption is mainly monitored by hydrophobic interactions with the surfactant, for $\mathrm{pH}$ values close to the 
pKa of p-nitrophenol, additional electrostatic forces occur between the negative charges of pnitrophenol and positive charges of the surfactant adsorbed via hydrophobic interactions with the first molecules of surfactant fixed on the carboxylate functions of the beads; $p$ nitrophenol is then better adsorbed in its phenolate form. This had already been shown in the literature ([20][53]) but we quantified the proportion of each kind of interaction. In addition, if the adsolubilisation phenomena have already been widely described in the case of simple systems, few studies have been conducted with complex systems formed by a gel of biopolymer associated with nanoparticles and a surfactant. This experimental work may be useful in future studies of such complex systems. On the other hand, it may contribute to the removal of weakly ionisable or non-ionic pollutant from water because most of the adsorbents currently under development are used to extract ionic pollutants. That could be useful in treatment of emerging pollutants in wastewater [54]. In addition, magnetic biopolymer composites are emerging materials and their use in water treatment could result in markedly improved performances features over conventional adsorption methods [55]. The magnetic beads could be quickly separated and recovered using an external magnetic field reducing costs, extraction time and secondary pollution.

\section{Acknowledgements:}

The authors are very grateful to Noëlle Dali for her scientific assistance.

\section{References}

[1] R. Lagoa, J.R. Rodrigues, Appl. Biochem. Biotechnol. 143 (2007) 115.

[2] X. Liu, L. Zhang, Powder Technol. 277 (2015) 112.

[3] Y. Zhang, W. Yan, Z. Sun, C. Pan, X. Mi, G. Zhao, J. Gao, Carbohydr. Polym. 117 (2015) 657.

[4] A. Hassani, R.D.C. Soltani, S. Karaca, A. Khataee, J. Ind. Eng. Chem. 21 (2015) 1197. 
[5] S.G. Nanaki, G.Z. Kyzas, A. Tzereme, M. Papageorgiou, M. Kostoglou, D.N.

Bikiaris, D.A. Lambropoulou, Colloids Surf. B Biointerfaces 127 (2015) 256.

[6] S. Barreca, S. Orecchio, A. Pace, Appl. Clay Sci. 99 (2014) 220.

[7] Q. Zhang, S. Deng, G. Yu, J. Huang, Bioresour. Technol. 102 (2011) 2265.

[8] A. Ely, M. Baudu, M.O.S.O. Kankou, J.-P. Basly, Chem. Eng. J. 178 (2011) 168.

[9] M. Lezehari, J.-P. Basly, M. Baudu, O. Bouras, Colloids Surf. Physicochem. Eng. Asp. 366 (2010) 88.

[10] D. Wang, L. Liu, X. Jiang, J. Yu, X. Chen, X. Chen, Appl. Surf. Sci. 329 (2015) 197.

[11] S. Tao, C. Wang, W. Ma, S. Wu, C. Meng, Microporous Mesoporous Mater. 147 (2012) 295.

[12] S. Hozhabr Araghi, M.H. Entezari, Appl. Surf. Sci. 333 (2015) 68.

[13] D.-W. Cho, B.-H. Jeon, C.-M. Chon, F.W. Schwartz, Y. Jeong, H. Song, J. Ind. Eng. Chem. In Press (2015).

[14] R. Jiang, J. Tian, H. Zheng, J. Qi, S. Sun, X. Li, J. Environ. Manage. 155 (2015) 24.

[15] L. Obeid, A. Bée, D. Talbot, S.B. Jaafar, V. Dupuis, S. Abramson, V. Cabuil, M. Welschbillig, J. Colloid Interface Sci. 410 (2013) 52.

[16] A. Bée, D. Talbot, S. Abramson, V. Dupuis, J. Colloid Interface Sci. 362 (2011) 486.

[17] V. Rocher, A. Bee, J.-M. Siaugue, V. Cabuil, J. Hazard. Mater. 178 (2010) 434.

[18] H.Y.Zhu, R. Jiang, L. Xiao, G.M. Zeng, Bioresour. Technol. 101 (2010) 5063.

[19] S. Yang, M. Gao, Z. Luo, Q. Yang, Chem. Eng. J. 268 (2015) 125.

[20] J. Xie, W. Meng, D. Wu, Z. Zhang, H. Kong, J. Hazard. Mater. 231-232 (2012) 57.

[21] Q. Xie, J. Xie, Z. Wang, D. Wu, Z. Zhang, H. Kong, Microporous Mesoporous Mater. 179 (2013) 144.

[22] V. Monticone, M.H. Mannebach, C. Treiner, Langmuir 10 (1994) 2395.

[23] V. Monticone, P. Favoriti, D. Lemordant, C. Treiner, Am. Chem. Soc. (1999).

[24] H. Nourmoradi, M. Nikaeen, M. Khiadani (Hajian), Chem. Eng. J. 191 (2012) 341. 
[25] S. Koner, A. Pal, A. Adak, Desalination 276 (2011) 142.

[26] S. Chatterjee, D.S. Lee, M.W. Lee, S.H. Woo, Bioresour. Technol. 100 (2009) 3862.

[27] A. Pal, S. Pan, S. Saha, Chem. Eng. J. 217 (2013) 426.

[28] X. Zhao, Y. Shi, Y. Cai, S. Mou, Environ. Sci. Technol. 42 (2008) 1201.

[29] A. Soni, A. Tiwari, A.K. Bajpai, Afr. J. Pure Appl. Chem. 6 (2012) 161.

[30] S. Mukdasai, N. Butwong, C. Thomas, S. Srijaranai, S. Srijaranai, Arab. J. Chem. In Press (2015).

[31] K.I. Draget, C. Taylor, Diet. Fibre Bioact. Polysacch. 25 (2011) 251.

[32] C. Lamelas, F. Avaltroni, M. Benedetti, K.J. Wilkinson, V.I. Slaveykova, Biomacromolecules 6 (2005) 2756.

[33] J.-M. Li, X.-G. Meng, C.-W. Hu, J. Du, Bioresour. Technol. 100 (2009) 1168.

[34] Z. Aksu, Process Biochem. 40 (2005) 997.

[35] V. Monticone, M.H. Mannebach, C. Treiner, Langmuir 10 (1994) 2395.

[36] L. Obeid, N. El Kolli, N. Dali, D. Talbot, S. Abramson, M. Welschbillig, V. Cabuil, A. Bée, J. Colloid Interface Sci. 432 (2014) 182.

[37] R. Massart, IEEE Trans. Magn. 17 (1981) 1247.

[38] N. Fauconnier, A. Bee, J. Roger, J.N. Pons, J. Mol. Liq. 83 (1999) 233.

[39] L. Gunnar Sillen, A.E. Martell, Stability Constants of Metal-Ion Complexes Section II $\square$ : Organic Ligands, Burlington House, London, 1964.

[40] J.C. Bacri, R. Perzynski, D. Salin, V. Cabuil, R. Massart, J. Magn. Magn. Mater. 62 (1986) 36.

[41] A. Ely, M. Baudu, J.-P. Basly, M.O.S.O. Kankou, J. Hazard. Mater. 171 (2009) 405.

[42] J.-M. Li, X.-G. Meng, C.-W. Hu, J. Du, Bioresour. Technol. 100 (2009) 1168.

[43] W.S.W. Ngah, S. Fatinathan, Colloids Surf. Physicochem. Eng. Asp. 277 (2006) 214.

[44] G. Crini, L. Janus, M. Morcellet, G. Torri, N. Morin, J. Appl. Polym. Sci. 73 (1999) 2903. 
[45] A. Kumar, S. Kumar, S. Kumar, D.V. Gupta, J. Hazard. Mater. 147 (2007) 155.

[46] B. Sarkar, Y. Xi, M. Megharaj, G.S.R. Krishnamurti, R. Naidu, J. Colloid Interface Sci. 350 (2010) 295.

[47] M. Akçay, G. Akçay, J. Hazard. Mater. 113 (2004) 189.

[48] W.S.W. Ngah, S. Fatinathan, Colloids Surf. Physicochem. Eng. Asp. 277 (2006) 214.

[49] G. Crini, L. Janus, M. Morcellet, G. Torri, N. Morin, J. Appl. Polym. Sci. 73 (1999) 2903.

[50] M. Akçay, G. Akçay, J. Hazard. Mater. 113 (2004) 189.

[51] B. Sarkar, Y. Xi, M. Megharaj, G.S.R. Krishnamurti, R. Naidu, J. Colloid Interface Sci. 350 (2010) 295.

[52] T. Behrends, S. Holzheu, R. Herrmann, Acta Hydrochim. Hydrobiol. 27 (1999) 422.

[53] W. Huang, C. Yao, S. Jin, S. Ying, X. Shen, J. Hazard. Mater. 155 (2008) 225.

[54] T. Deblonde, C. Cossu-Leguille, P. Hartemann, Int. J. Hyg. Environ. Health 214 (2011) 442.

[55] D.H.K. Reddy, S.-M. Lee, Adv. Colloid Interface Sci. 201-202 (2013) 68. 
